\title{
Introduction: The trouble with forest: definitions, values and boundaries
}

\author{
Muriel Côte $^{1}$, Flurina Wartmann ${ }^{2}$, and Ross Purves ${ }^{1,3}$ \\ ${ }^{1}$ Department of Geography, University of Zürich, Zürich, Switzerland \\ ${ }^{2}$ Eidgenössiche Forschungsanstalt für Wald, Schnee \\ und Landschaft (WSL), Birmensdorf, Switzerland \\ ${ }^{3}$ URPP Language and Space, University of Zürich, Zürich, Switzerland \\ Correspondence: Muriel Côte (muriel.cote@geo.uzh.ch)
}

Received: 20 March 2018 - Revised: 31 August 2018 - Accepted: 17 September 2018 - Published: 9 October 2018

\begin{abstract}
Forest is in trouble. The most recent (2015) FAO Forest Resources Assessment shows an encouraging trend towards a decrease in deforestation rates, but it also points out that since 1990 total forest loss corresponds to an area the size of South Africa. Efforts to curtail deforestation require reliable assessments, yet current definitions for what a forest exactly is differ significantly across countries, institutions and epistemic communities. Those differences have implications for forest management efforts: they entail different understandings about where exactly a forest starts and ends, and therefore also engender misunderstandings about where a forest should start and end, and about how forests should be managed. This special issue brings together different perspectives from practitioners and academic disciplines - including linguistics, geographic information science and human geography - around the problem of understanding and characterizing forest. By bringing together different disciplinary viewpoints, we hope to contribute to ongoing interdisciplinary efforts to analyse forest change. In this introduction, we propose that interrogating the relationship between forest definitions, boundaries and ways of valuing forests constitutes a productive way to critically conceptualize the trouble that forest is in.
\end{abstract}

\begin{abstract}
"In urgent times, many of us are tempted to address trouble in terms of making an imagined future safe, of stopping something from happening that looms in the future, of clearing away the present and the past in order to make futures for coming generations. Staying with the trouble does not require such a relationship to times called the future. In fact, staying with the trouble requires learning to be truly present, not as a vanishing pivot between awful or edenic pasts and apocalyptic or salvific futures, but as mortal critters entwined in myriad unfinished configurations of places, times, matters, meanings."
\end{abstract}

(Donna Haraway, 2016:1 Staying with the Trouble: Making kin in the Chthulucene)

\section{The trouble with forest}

Forest is in trouble not only because forest cover is changing rapidly, but also because our ways of categorizing forests are never stable. In this special issue we do not aim to solve the trouble but rather to, as Haraway suggests, learn from it. As she notes in her latest book, "trouble" is an interesting word; it refers not only to there being a problem but also to an objective kind of ambiguity that is at the heart of a given problem. In this introduction, we propose to open the "black box" of trouble that we understand as cutting across three concepts - definitions, values and boundaries. Disentangling these concepts, and their relations, helps us derive fundamental questions for a critical - in the sense of Lave et al. (2014) - assessment of the kind of trouble forest is in. Through these concepts and questions, we are not trying to solve questions such as "where do forests start (and end)?" Rather, we wish to make a conceptual contribution to show why making sense of such a seemingly simple question remains elusive. 
Putting forest policy into practice generally requires spatial planning and, inevitably, the specification of forest boundaries, which becomes difficult where forest definitions are contested - especially as policy and planning seek to be relevant at increasingly broad scales. Yet agreeing on forest definitions is not easy. As Chazdon et al. (2016) have shown, definitions are not produced in a vacuum. They are always to some extent adopted to fit a particular purpose and are thus as much a product of the intentions of the describer (here, mostly scientists but also policymakers) as of the thing they describe (in our case forest). Consequently, forest definitions are subject to some forms of valuation. Value here is not meant in the sense of liking certain ecological characteristics more than others, but in the sense of seeing certain ones rather than others. An example of such valuation is articulated in the work of Ghazoul and Chazdon (2017) on what counts as ecosystem degradation and recovery. They conclude that "[d]efining degradation independently of humancentered utility functions, based on purely biophysical processes, can minimize the influence of value judgments that otherwise clouds definitional clarity but might not necessarily facilitate shared understanding or concern among diverse stakeholders. Thus, biophysical attributes of degradation can be quantified and measured, but the relevance of selected attributes remains subject to values that determine preferred states." (Ghazoul and Chazdon, 2017:167). In other words, definitions are of little use if they are made without a concern for "human-centred utility" values that give them relevance. Such values are not universal however, and this is reflected in a multiplicity of forest definitions.

Our thinking emerged from discussions that took place during a workshop that we organized in 2016 around the theme of "the trouble with defining forests - semantics, ontology, territoriality". It gathered the authors of the articles that make up this special issue, and other academic and conservation practitioner colleagues in Switzerland and from abroad, with expertise in the fields of land cover/land use science, linguistics and political ecology. We focused on disciplinary and cross-disciplinary struggles that take place on the ground and in the map-making lab, around defining forest both semantically and spatially. Together the papers follow up on the questions and insights brought up at the workshop, interrogating the seemingly straightforward notion of forest. Rather than restating critiques of current definitions and definition makers, this multidisciplinary themed issue aims to show that gaps and divergences between forest definitions across places, times, disciplines and communities of practice - are a productive common working ground, as suggested by Nightingale (2003, 2009). What the papers have in common is a motivation to reach out beyond disciplinary trenches, and below we propose that querying the relation between forest definitions, boundaries and values constitutes a good way to reach that aim - as concepts to think with, rather than to explain or predict - and towards more critical, yet also more inclusive, ways of imagining the trouble that forest is in.

\section{Forest trouble between continuity and change}

That forest is a fuzzy and political category is not a new claim, yet it is not a concern of the past either. In Misreading the African Landscape Leach and Fairhead (1996) drew attention to the caveats of postcolonial environmental orthodoxies in Guinean forest savannah mosaics. They demonstrated the role that colonial history and science played in misreading contemporary forest islands in Guinea as endangered forest remnants, rather than the product of careful human management. This work was seminal in the development of a science of tree-people relationships in the field of political ecology that has endeavoured to critically examine national and international scientific and associated policy approaches to forest management (Fairhead and Leach, 1998). It puts a finger on a general theoretical problem: land change science has demonstrated the co-existence of different, and sometimes competing, landscape ontologies. Forest is entangled in enduring policy and scientific categorizations such as "degraded", "untouched" or "primary/secondary" that continue to be contested (Hecht et al., 2014:8). But, because technology and policy have moved on and because environmental and societal needs have changed, these concerns must be revisited.

With regards to policy, the concentration of interest around the role of $\mathrm{CO}_{2}$ emissions as a driver of climate change and normalization of "carbon" as a part of our daily lives, conversations and concerns has revived and deeply transformed the kind of attention that "forests" receive. It seems that we should no longer be concerned with conserving forests, but rather we should be concerned with their ability to capture emissions differentially. This of course transforms the way we value forest landscapes and tree species comparatively to one another, but it also transforms the relations between humans about forests (Scoones and Leach, 2015). For example, the beguilingly simple idea that underlies REDD+ (Reducing Emissions from Deforestation and Forest Degradation) - that high-emission rich countries pay low-emission poorer ones to conserve forests with the best potential to capture $\mathrm{CO}_{2}$ - relies on problematic forest definitions. In the case of Tanzania, Beymer-Farris and Bassett (2012:333) explain that these definitions "do not take into consideration the environmental history or the agency of forest-reliant communities in the making of forested landscapes". This trouble in defining and valuing forest lies at the heart of the resistance, disappointments and localized conflicts related to contemporary forest policy (Friis Lund et al., 2017; Leach and Scoones, 2015; Benjaminsen, 2014; Fairhead et al., 2012).

Conversely, policy sometimes stays the same even though its context has changed. A striking example is the law concerning forests in Switzerland. In the 19th century, massive deforestation in alpine regions in Switzerland led to a surge in natural catastrophes such as avalanches and mud slides. Calls were made to protect forests in order to safeguard human settlements and infrastructure. Thus, in 1876 the first 
law to protect forests was passed, the "Waldgesetz" (forest law), which states that the total area covered by forest as well as its spatial distribution are to remain the same (Fédération Suisse, 1991). Despite some minor amendments, the forest has remained strongly protected since 1876 . However, changing contexts in the agrarian and forestry sectors, for example, loss of highly biologically diverse agrarian meadows to forest regrowth at higher altitudes, call into question the usefulness of such strict forest definitions (NZZ, 31 July 2013). These changes in how forest is valued - as protection from natural hazards or a danger to biodiversity - demonstrate that continuity in definitions can also lead to conflicts, as societal needs and thus society's way of valuing forest change.

Finally, theories about changes in forest dynamics have evolved and require that we continue paying attention to the categories we use. This is illustrated in the case of the much-debated "forest transition theory", contested in part because it equates forest recovery with economic modernization (Perz, 2007; Putz and Redford, 2010; Kozak and Swagrzyk, 2016 - see also Kull, 2017, in this issue). Another example is the uncertainty that clouds analysis of carbonsink behaviour (Erb et al., 2013), which makes “today's forest management [...] more of a gamble than a scientific debate" according to some, partly because it is grounded in scientific assumptions about "managed" and "unmanaged" forests (Bellassen and Luyssaert, 2014:155). A third example is the emerging debate about the differentiation between "primary" and "intact" forests (Mackey et al., 2015; Watson et al., 2018). These three examples illustrate that forest categories continue to be at the heart debates about forest dynamics. We propose below that these debates are illuminated through a reflexive approach to definitions that explore how forests are valued and bounded.

\section{Definitions, values and boundaries}

"Land spanning more than 0.5 hectares with trees higher than 5 meters and a canopy cover of more than 10 percent, or trees able to reach these thresholds in situ. It does not include land that is predominantly under agricultural or urban land use". 1

This definition was used by the FAO for its Forest Resource Assessments in 2010 and 2015, the most comprehensive global assessment of forest and forestry to date. It has become a baseline for the work of the FAO, but it was a challenging report to put together, in part because of the variety of ways in which different countries define forests (Grainger, 2007; Keenan et al., 2015). Indeed the FAO definition is only one of many possible definitions for forests. Land cover change scientists mobilize myriad ways of defining both what a forest is and where forest starts and ends. Our

\footnotetext{
${ }^{1}$ http://www.fao.org/3/a-i4808e.pdf, last access: 13 March 2018.
}

updated version of a figure originally drawn by Comber et al. $(2005: 201)$ illustrates the breadth of ways in which forest can be defined by different countries using the simple terms "tree height" and "canopy cover", which must in turn be operationalized and extracted, typically with remote sensing, if estimates are to be made over large areas (Koetz et al., 2007).

This heterogeneity becomes a problem when widely manipulated information is treated as data, whereas neither the breadth of the semantics nor the meaning of this information is understood. It is especially problematic currently, where producing international (and thus cross-border) forest data and internationally translatable benchmarks for changing forest dynamics is needed (Soares-Filho et al., 2016). Furthermore, regions are not equal with regards to heterogeneity: in a recent paper Sexton et al. (2015) mapped the level of consensus over definitions, showing that, among the $800+$ different official definitions of forests analysed, the highest level of uncertainty occurred in the most sparsely treed regions.

Such "uneven heterogeneity" manifests itself beyond scientific knowledge production. It recently flared up into a controversy involving a misunderstanding between scientists and forest management practitioners about "grasslands". The misunderstanding followed the publication by the World Resource Institute (WRI) and the International Union for the Conservation of Nature (IUCN) of a "forest restoration" map indicating both deforested lands and grassy biomes such as grasslands, savannas and open woodlands as suitable candidate areas for replantation projects, which grassybiome ecologists labelled a "tyranny of trees" (Veldman et al., 2015a, b; Laestadius et al., 2015; Rojas-Briales, 2015; Bond, 2016). So definition is an ever-pressing concern in a global(izing) context, but the conflation between the data generated to describe forest change and data used to prescribe policies that address forest change is problematic. If countries do not actually define forests in the same way, standardized prescriptions risk imposing unfair, and ecologically inadequate, forest policy recommendations globally. The fact that a global demand for forest benchmarks is growing as global mitigation schemes - such as payment for ecosystem services and REDD+ - gather pace only leaves one to wonder what to do with such heterogeneity in forest definitions (Gupta et al., 2013).

In addition our endeavours to produce and refine descriptive categories are (and maybe should be) driven by our assumptions and perceptions about what problems (or trouble) there might be with forest, our values in other words. Such assumptions and perceptions vary widely, and of course what problems there might be depends on who exactly is looking (Chazdon et al., 2016). This is demonstrated in the work of Robbins (1998a, b, 2001, 2003) in Rajasthan. He compares and contrasts the identification of forest areas by local forest users and foresters, focusing on an area populated by an invasive Prosopis subspecies, which is, contrary to the foresters' perception, not identified as "forest" by forest users. Despite this divergence from forest users' representations, Robbins 


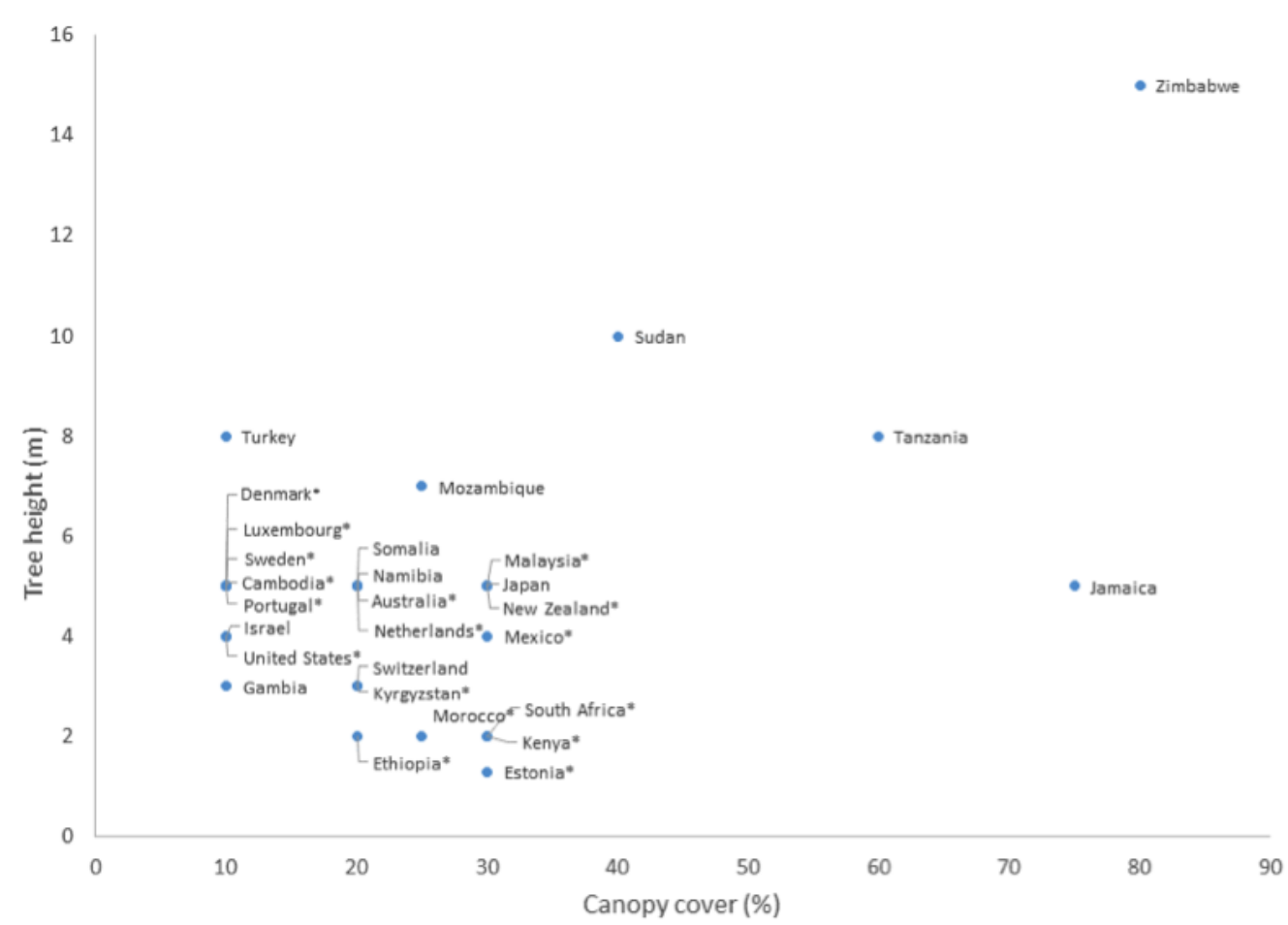

Figure 1. Minimum physical requirements of a "forest" in terms of tree height and canopy cover according to Lund (2018). * indicates use of UNFCCC data for this country. This figure uses the same countries as the original (Comber et al., 2005:201).

describes how the category "forest" becomes literally naturalized, both on the map and on the ground, through the convergent representations of a remote-sensing technology and a forest bureaucracy that needs to reproduce itself. The take-home message is that the variation between definitions reflects diversity in values, and it boils down to acknowledging the partiality of knowledge. No point of view - or technology, for example in the form of remote sensing or geographic information systems - is neutral. As Nightingale (2003) pointed out using similar methodology to Robbins' in Nepal, what separates what is and what is not forest, both on the map and in the landscape, reflects particular ways of knowing nature. These ways of knowing are embedded in the different narratives available to us (whoever we might be) about the potential causes of the problem - like deforestation - at hand (Ribot 1999; Ostrom and Nagendra 2006; Goldman et al., 2011).

The complicated relationship - the trouble - between forest definitions and values is not only a case of doing good science - science that states explicitly its assumptions and that makes its analysis transparent and challengeable. In practice the link between definitions and values is often silent and challenging to investigate because these silences reflect power. This power often becomes more visible when boundaries are drawn. Indeed the value-laden quality of definitions has both political origins and political effects. Firstly, it has political origins in the sense that the values underly- ing definitions, and reflected in boundaries, result from uneven relations of power between hegemonic and subaltern world views. Scientific knowledge about forest dynamics has tended to reify experts' perspectives, to the detriment of forest users' - for example, that of the millions of indigenous people around the world who dwell in forests and make use of forest resources (International Alliance of IndigenousTribal Peoples of the Tropical Forest, 1996; United Nations, 2009). The resulting drive for an inclusion of "indigenous knowledge" about forest resources has become an imperative in many places since the 1990s, exemplified through "counter-mapping practices" in the area of forest management (Peluso, 1995). This shift has been particularly powerful in producing alternative forest management prescriptions (e.g. community-based natural resource management). However, the limits that these initiatives face (local elite capture, discharge of state responsibility onto communities) also demonstrate that "adding in" indigenous knowledge cannot resolve the trouble between value-laden definitions and boundaries, because, regardless of how much "indigenous knowledge" is included, the relation between forest definitions and the forest boundaries that are drawn with pens and fences never occurs in a political vacuum (Agrawal, 1995).

Secondly, the values underlying definitions are made visible when looking at boundaries because definitions are often used as political currency to exercise political control over territory. The work of Vandergeest and Peluso (2015) 
on the "political forests" of Indonesia is a case in point. They show that the category "forest" used in policy prescription is not only the product of a well-informed scientific assessment of where forests are, or a wishful prescription of where they should be, but also a tool for governing the people and places within the areas earmarked as forest. Indeed they trace transformations in the policy characterization of forests from colonial to current times and demonstrate their concomitance with different epochs involving government violence towards its population. Conversely, forest categories can become powerful ways for subaltern groups to leverage political rights over certain territories. An interesting example is the inclusion of forest users in the elaboration of measuring, reporting and verification (MRV) mechanisms in implementing REDD+ schemes. McCall et al. (2016) show the challenges in implementing such participatory MRV mechanisms in Mexico, where forest users divulged ecological and cultural information that was often territorially sensitive. Such information could be levered in territorial or property claims, or bring the risk of eco-piracy if forest users mapped out sacred places, rare plants and minerals.

The power relations underlying value-laden definitions also have ecological implications. Typical examples include the problematic inclusion of monoculture plantations as areas recognized as "forest", or the proliferation of invasive species as cases of "successful afforestation" (Sandbrook et al., 2010; Bruggeman et al., 2015; Heilmayr et al., 2016). But power relations underlying different ways of valuing and therefore defining forests are not undesirable "noise" that can be supressed. This is why the relations between forest definitions, values and boundaries can provide fruitful ground for reflection on the trouble with forest.

\section{The papers}

The papers in the theme issue all address, from different viewpoints, the trouble with forest definitions, boundaries and values. An excellent entry point to starting discussions on categories is semantics. The contribution to the themed issue by Burenhult et al. (2017) offers an illuminating perspective on the concept of "forest" from the perspective of linguistics. It explores how, or indeed if, "forest" is conceptualized in six different indigenous languages, or speech communities, throughout the world, paying specific attention to the significance of the presence of trees' height and cover as factors in explaining semantics. Fascinatingly, these factors are much less determinant than a number of other semantic categories and dichotomies that appear repeatedly within their cross-linguistic and cross-cultural analysis: inside-outside, containment, (un)inhabited space. They demonstrate that "forest" is neither a cross-linguistically nor a cross-culturally recognized category. Yet rather than discouraging standardization, this paper refines our understand- ing of where forest meanings converge and diverge and lays out a rich terrain for further potential investigations.

Frick et al. (2018) investigate the different values people attach to forests in Switzerland at different points in time and relate these to prevailing (national) discourses about the values of forests. They bring up interesting mismatches between their survey and official discourses and demonstrate the difficulty of forest management when the perceptions of forest users mismatch those of policymakers. In some cases, multiple forest ontologies manifest into competing claims to forest management regimes, and competing attempts at ruling forest become an integral part of defining where a forest starts and ends. Côte and Gautier (2018) take up this issue with an analysis of the persistence of historical forest definitions in Burkina Faso. They demonstrate the stubbornness of administrative forest boundaries in spite of changes through what they term "fuelwood territorialities", emphasizing the role of unofficial resource economics in shaping where a forest officially starts and ends.

The final two papers are pragmatic propositions as to what to do with the heterogeneity of forest definitions, given their value and power-laden nature, for contemporary forest science and policy frameworks. Indeed, as the "tyranny of trees" controversy illustrates (Veldman et al., 2015b), scientists are also integral participants, rather than mere observers, in the power-laden process of defining, valuing and bounding forest. Kull's (2017) paper speaks to the scientific framework of forest transition. He proposes revisiting the categories that form the building blocks of earlier forest transition theory, but in a way that accounts for both multiple forest ontologies and multiple intentions for areas under forest transition. His conceptual approach lays the groundwork for a potential way forward to defining forest in a way that makes visible currently divergent definitions and views of forests.

Lastly, Comber and Kuhn (2018) propose an approach addressing the fundamental problem of homogenizing forest standards. They explore the mismatch between global projects' forest definitions, such as REDD+, which attempt to value forest, their standard-driven implementation, and alternative local views and understandings of forests. Querying the relation between competing forest ontologies and their territorial operationalization helps to generate questions about the material implications of forest science. They lay out an approach based on "data primitives" aiming to both define and bound forest based around multiple dimensions derived from diverse understandings of forest.

We argue that, as illustrated by these papers, at the heart of debates about forests lie neither boundaries nor definitions but rather values. These can be reflected explicitly, for example in expert and non-expert perspectives as illustrated by Frick et al. (2018), or be implicit, for instance in the ways that language is used to conceptualize forest as a category (e.g. Burenhult et al., 2017). Our argument is that understanding how and by whom forest is valued is an essential way to understand and expose the trouble inherent in our ways of 
thinking about forest, and through reflecting on such values we can better understand how definitions and boundaries are produced and used.

Thus, differences between ways forests are defined by scientists and the application of these definitions when policies land on the ground is not only a case of finding the right "fit" (Nightingale, 2011). The tension between forest definitions, values and boundaries is inevitable, but it becomes problematic when it is ignored (c.f. Côte and Gautier, 2018). We therefore propose that forest is in trouble when the relationship between definitions and values is silenced or smoothed over. Adjusting institutional design relies on the fundamental assumption that competing interests - between scientists, forest users, bureaucrats and conservationists - can all be satisfied. However, such conflicts of interest - in representing a certain area as forest, or not, and in adopting a particular definition of "forest" rather than another - are not simply "errors" or "noise" to be removed. Rather than discarding such issues as institutional or definitional misfits, the relation between value-laden definitions and boundaries reminds us that forests also stand for something else: political rights to land, territory and political recognition.

We therefore argue for giving greater scientific space to the silences involved in the valuation of environmental knowledge. Only by staying with these questions can we aspire to understand why the heterogeneity of forest definitions persists and what exactly the discrepancies between them mean (Watkins et al., 2017; Lave et al., 2014). Epistemic differences between groups as diverse as scientists, foresters, forest resource gatherers and national policymakers who work on forests need to be discussed more explicitly in order to better understand, analyse and address the kind of trouble that forest is in. This is why we chose to publish this collection of papers in the open-access Geographica Helvetica, an ideal platform to host and inclusively stage a discussion about the trouble with and between forest definitions, boundaries and values. Crucially, by publishing in an open-access outlet, all those interested in such interdisciplinary debates can engage, participate and learn from them. This is important, because disciplinary differences often force us to reflect on seemingly obvious ideas and critically re-evaluate them. We believe that truly interdisciplinary efforts, such as this special issue, exploring the trouble with forest, yield more than simply the sum of their parts and can be effective ways of "staying with the trouble".

Data availability. No data sets were used in this article.

Competing interests. The authors declare that they have no conflict of interest.
Acknowledgements. We are grateful to the anonymous reviewers for their constructive and thoughtful comments on a draft version of this paper. We would also like to thank the participants at the workshop in Stels on "the trouble with defining forest: semantics, ontology, territoriality" in June 2016 for their comments and discussions that contributed to the ideas in this paper. Any errors in this paper remain of course our own.

Edited by: Benedikt Korf

Reviewed by: two anonymous referees

\section{References}

Agrawal, A.: Dismantling the divide between indigenous and scientific knowledge, Dev. Change, 26, 413-439, 1995.

Bellassen, V. and Luyssaert, S.: Carbon sequestration: managing forests in uncertain times, Nature, 506, 153-155, 2014.

Benjaminsen, G.: Between resistance and consent: project-village relationships when introducing REDD+ in Zanzibar, Forum for Dev. Studies, 41, 377-398, 2014.

Beymer-Farris, B. A. and Bassett, T. J.: The REDD menace: resurgent protectionism in Tanzania's mangrove forests, Global Environ. Change, 22, 332-341, 2012.

Bond, W. J.: Ancient grasslands at risk, Science, 351, 120-122, 2016.

Bruggeman, D., Meyfroidt, P., and Lambin, E. F.: Production forests as a conservation tool: effectiveness of Cameroon's land use zoning policy, Land Use Policy, 42, 151-164, https://doi.org/10.1016/j.landusepol.2014.07.012, 2015.

Burenhult, N., Hill, C., Huber, J., van Putten, S., Rybka, K., and San Roque, L.: Forests: the cross-linguistic perspective, Geogr. Helv., 72, 455-464, https://doi.org/10.5194/gh-72-455-2017, 2017.

Chazdon, R. I., Brancalion, P. H. S., Laestadius, L., BennettCurry, A., Buckingham, K., Kumar, C., Moll-Rocek, J., Guimarães Vieira, I. C., and Wilson, S. J.: When is a forest a forest? Forest concepts and definitions in the era of forest and landscape restoration, Ambio, 45, 538-550, https://doi.org/10.1007/s13280-016-0772-y, 2016.

Comber, A. and Kuhn, W.: Fuzzy difference and data primitives: a transparent approach for supporting different definitions of forest in the context of REDD+, Geogr. Helv., 73, 151-163, https://doi.org/10.5194/gh-73-151-2018, 2018.

Comber, A., Fisher, P., and Wadsworth, R. A.: What is land cover?, Environ. Plann. B, 32, 199-209, 2005.

Côte, M. and Gautier, D.: Fuelwood territorialities: Chantier d'Aménagement Forestier and the reproduction of "political forests" in Burkina Faso, Geogr. Helv., 73, 165-175, https://doi.org/10.5194/gh-73-165-2018, 2018.

Erb, K.-H., Kastner, T., Luyssaert, S., Houghton, R. A., Kuemmerle, T., Olofsson, P., and Haberl, H.: Bias in the attribution of forest carbon sinks, Nat. Clim. Change, 3, 854-856, 2013.

Fairhead, J., Leach M., and I. Scoones, I. (Eds.): Green grabbing: a new appropriation of nature, J. Peasant Stud., 39, 237-261, 2012.

Fairhead, J. and Leach, M. (Eds.): Reframing deforestation: global analyses and local realities, Studies in W. Afr., Global Environ. Change Series, Routledge, London, 1998.

Fédération Suisse: Loi fédérale sur les forêts, edited by: L'Assemblée fédérale de la Confédération, Confédération Suisse, 1991. 
Frick, J., Bauer, N., von Lindern, E., and Hunziker, M.: What forest is in the light of people's perceptions and values: socio-cultural forest monitoring in Switzerland, Geogr. Helv., in press, 2018.

Friis Lund, J., Sungusia, E., Bukhi Mabele, M., and Scheba, A.: Promising change, delivering continuity: REDD+ as conservation fad, World Dev., 89, 124-139, 2017.

Ghazoul, J. and Chazdon, R. I.: Degradation and recovery in changing forest landscapes: a multiscale conceptual framework, Annu. Rev. Env. Resour., 42, 1-29, 2017.

Goldman, M. J., Nadasdy, P., and Turner, M. D. (Eds.): Knowing Nature. Conversations at the Intersection of Political Ecology and Science Studies, University Chicago Press, Chicago, 2011.

Grainger, A.: The influence of end-users on the temporal consistency of an international statistics process: the case of tropical forest statistics, J. Off. Stat., 23, 553-592, 2007.

Gupta, J., van der Grijp, N., and Kuik, O. (Eds.): Climate Change, Forests and REDD: Lessons for Institutional Design, Routledge, London, 2013.

Hecht, S. B., Morrison, K. D., and Padoch, C.: From fragmentation to forest resurgence: paradigms, representations, and practices, in: The Social Lives of Forests, edited by: Hecht, S. B., Morrison, K. D., and Padoch, C., The University of Chicago Press, Chicago, 1-13, 2014.

Heilmayr, R., Echeverría, C., Fuentes, R., and Lambin, E. F.: A plantation-dominated forest transition in Chile, Appl. Geogr., 75, 71-82, 2016.

International Alliance of Indigenous-Tribal Peoples of the Tropical Forest and International Work Group for Indigenous Affairs: Indigenous peoples, forest and biodiversity, published by: International Alliance of Indigenous-Tribal Peoples of the Tropical Forest, and International Work Group for Indigenous Affairs, London, 1996.

Keenan, R. J., Reams, G. A., Achard, F., de Freitas, J. V., Grainger, A., and Lindquist, E.: Dynamics of global forest area: results from the FAO Global Forest Resources Assessment 2015, Forest Ecol. Manag., 352, 9-20, 2015.

Koetz, B., Sun, G., Morsdorf, F., Ranson, K. J., Kneubühler, M. , Itten, K., and Allgöwer, B.: Fusion of imaging spectrometer and LIDAR data over combined radiative transfer models for forest canopy characterization, Remote Sens. Environ., 106, 449-459, 2007.

Kozak, J. and Szwagrzyk, M.: Have there been forest transitions? Forest transition theory revisited in the context of the modifiable areal unit problem, Area, 48, 504-512, 2016.

Kull, C. A.: Forest transitions: a new conceptual scheme, Geogr. Helv., 72, 465-474, https://doi.org/10.5194/gh-72-4652017, 2017.

Laestadius, L., Maginnis, A., Minnemeyer, S., Potapov, P. V., Reytar, K., and Saint-Laurent, C.: Sparing grasslands: map misinterpreted, Science, 347, 1210-1211, 2015.

Lave, R., Wilson, M. W., Barron, E. S., Biermann, C., Carey, M. A., Duvall, C. S., Johnson, L., Lane, K. M., McClintock, N., Munroe, D., Pain, R., Proctor, J., Rhoads, B. L., Robertson, M. M., Rossi, J., Sayre, N. F., Simon, G., Tadaki, M., and Van Dyke, C.: Intervention: Critical physical geography, Can. Geogr., 58, 1-10, 2014.

Leach, M. and Fairhead, J.: Misreading the African Landscape: Society and Ecology in a Forest-savanna Mosaic, Cambridge University Press, Cambridge, 1996.
Leach, M. and Scoones I.: Political ecologies of carbon in Africa, in: Carbon Conflicts and Forest Landscapes in Africa, edited by: Leach, M. and Scoones, I., Routledge, London, 1-14, 2015.

Lund, H. G.: rev* Definitions of forest, deforestation, afforestation, and reforestation, Forest Information Services, misc. pagination, Gainesville, VA, https://doi.org/10.13140/RG.2.1.2364.9760, 2018.

Mackey, B., DellaSala, D. A., Kormos, C., Lindenmayer, D., Kumpel, N., Zimmerman, B., Hugh, S., Young, V., Foley, S., Arsenis, K., and Watson, J. E. M.: Policy options for the world's primary forests in multilateral environmental agreements: policy options for world's primary forests, Conserv. Lett., 8, 139-147, https://doi.org/10.1111/conl.12120, 2015.

McCall, M. K., Chutz, N., and Skutsch, M.: Moving from Measuring, Reporting, Verification (MRV) of forest carbon to community Mapping, Measuring, Monitoring (MMM): perspectives from Mexico, PLoS ONE, 11, 1-22, 2016.

Nightingale, A.: A feminist in the forest: situated knowledges and mixing methods in natural resource managemen, ACME: Int. EJournal for Crit. Geogr., 2, 77-90, 2003.

Nightingale, A.: Triangulation, in: International Encyclopedia of Human Geography, edited by: Kitchin, R. and Thrift, N., Elsevier, Oxford, 489-492, 2009.

Nightingale, A.: Beyond design principles: subjectivity, emotion and the (ir)rational commons, Soc. and Nat. Resour., 24, 119132, 2011.

NZZ: Seit 1876 ist der Wald tabu, NZZ, available at: https: //www.nzz.ch/schweiz/seit-1876-ist-der-wald-tabu-1.18125617 (last access: 29 May 2017), 31 July 2013.

Ostrom, E. and Nagendra, H.: Insights on linking forests, trees, and people from the air, on the ground, and in the laboratory, P. Natl. Acad. Sci. USA, 103, 19224-19231, 2006.

Peluso, N. L.: Whose woods are these? Counter-mapping forest territories in Kalimantan, Indonesia, Antipode, 27, 383-406, 1995.

Perz, S. G.: Grand theory and context specificity in the study of forest dynamics: forest transition theory and other directions, Prof. Geogr., 59, 105-114, 2007.

Putz, F. and Redford, K.: The importance of defining "forest": tropical forest degradation, deforestation, long-term phase shifts, and further transitions, Biotropica, 42, 10-20, 2010.

Ribot, J. C.: A history of fear: imagining deforestation in the West African dryland forests, Global Ecol. Biogeogr., 8, 291-300, 1999.

Robbins, P.: Authority and environment: institutional landscapes in Rajasthan, India, Ann. Assoc. Am. Geogr., 88, 410-435, 1998a.

Robbins, P.: Paper forests: imagining and deploying exogenous ecologies in arid India, Geoforum, 29, 69-86, 1998b.

Robbins, P.: Fixed categories in a portable landscape: the causes and consequences of land-cover categorization, Environ. Plann. A, 33, 161-179, 2001.

Robbins, P.: Beyond ground truth: GIS and the environmental knowledge of herders, professional foresters, and other traditional communities, Hum. Ecol., 31, 233-253, 2003.

Rojas-Briales, E.: Sparing grasslands: FAO's active role, Science, 347, 1211, 2015.

Sandbrook, C., Nelson, F., Adams, W. M., and Agrawal, A.: Carbon, forests and the REDD paradox, Oryx, 44, 330-334, 2010.

Scoones, I. and Leach, M. (Eds.): Carbon Conflicts and Forest Landscapes in Africa, Routledge, London, 2015. 
Soares-Filho, B., Rajão, R., Merry, F., Rodrigues, H., Davis, J., Lima, L., Macedo, M., Coe, M., Carneiro, A., and Santiago, L.: Brazil's market for trading forest certificates, PLoS ONE, 11, 117, 2016.

Sexton, J. O., Noojipady, P., Song, X. P., Feng, M., Song, D. X., Kim, D. H., Anand, A., Huang, C., Channan, S., Pimm, S. L., and Townshend, J. R.: Conservation policy and the measurement of forests, Nat. Clim. Change, 6, 192-197, 2015.

United Nations: State of the world's indigenous peoples, edited by: Department of Economic and Social Affairs, United Nations, New York, 2009.

Vandergeest, P. and Peluso, N. L.: Political forests, in: Int. Handbook of Polit. Ecol., edited by: Bryant, R. L., Edward Elgar, Cheltenham, UK, 162-175, 2015.

Veldman, J. W., Overbeck, G. E., Negreiros, D., Mahy, G., Le Stradic, S., Fernandes, W. G., Durigan, G., Buisson, E., Putz, F. E., and Bond, W. J.: The tyranny of trees in grassy biomes, Science, 37, 484-485, 2015a.
Veldman, J. W., Overbeck, G. E., Negreiros, D., Mahy, G., Le Stradic, S., Fernandes, W. G., Durigan, G., Buisson, E., Putz, F. E., and Bond, W. J.: Where tree planting and forest expansion are bad for biodiversity and ecosystem services, BioScience, 65, 1011-1018, 2015b.

Watkins, C., Zavaleta, J., Wilson, S. J., and Francisco, S.: Developing an interdisciplinary and cross-sectoral community of practice in the domain of forests and livelihoods, Conserv. Biol., 32, 6071, 2017.

Watson, J. E. M., Evans, T., Venter, O., Williams, B., Tulloch, A., Stewart, C., Thompson, I., Ray, J. C., Murray, K., Salazar, A., McAlpine, C., Potapov, P., Walston, J., Robinson, J. G., Painter, M., Wilkie, D., Filardi, C., Laurance, W. F., Houghton, R. A., Maxwell, S., Grantham, H., Samper, C., Wang, S., Laestadius, L., Runting, R. K., Silva-Chávez, G. A., Ervin, J., and Lindenmayer, D.: The exceptional value of intact forest ecosystems, Nat. Ecol. Evolut., 2, 599-610, https://doi.org/10.1038/s41559018-0490-x, 2018. 